\title{
Successful Conception and Delivery in an Unusual Case of 46,XY Pure Gonadal Dysgenesis with Spontaneous Breast Development, Menses, and Bilateral Hydrosalpinx
}

\author{
${ }^{1}$ Pooja Singh, ${ }^{2}$ Aradhana Kalra, ${ }^{3}$ Purnima K Nadkarni, ${ }^{4}$ Kishore Nadkarni
}

\begin{abstract}
Aim: To study unusual presentations of 46XY pure gonadal dysgenesis (Swyer syndrome), implications of delayed diagnosis, importance of karyotype and early gonadectomy and pregnancy outcome with ART.
\end{abstract}

Background: To report a case of Swyer syndrome with spontaneous breast development, menses and bilateral hydrosalpinx with Successful pregnancy outcome.

Case description: 30 years old lady presented with primary infertility, secondary amenorrhea and normal secondary sexual characters. Sonography revealed small uterus with atrophic ovaries and B/L hydrosalpinx. Hormonal profile showed hypergonadotrophic hypogonadism and Karyotype was 46XY. Laparoscopic salpingectomy and gonadectomy was done. Histopathology revealed streak gonads with no evidence of malignancy and diagnosis of 46XY disorder of sexual development (DSD)/ Swyer syndrome was made. After endometrial preparation with ethinyl estradiol, patient conceived with allogenic oocytes and delivered preterm twins vaginally at 31 weeks.

Conclusion: Patients with Swyer Syndrome usually present at adolescence with delayed puberty and/or primary amenorrhea. However they can present late with secondary amenorrhea or just irregular, infrequent menses or primary infertility. Karyotype is mandatory in such cases and early gonadectomy improves long term survival as incidence of malignancy in the dysgenetic gonad is high. Incipient malignancy is usually the source of estrogen in patients with normal secondary sexual characters. Hypoplastic uterus is responsive to estrogen therapy in terms of enlargement and endometrial preparation and also this uterus may have the ability to respond to the process of labor and these patients can deliver vaginally.

Clinical significance: Early diagnosis and timely management of patients with dysgenetic gonads is important. Pregnancy is possible with allogenic oocytes. Genetic counseling and long term follow-up is required.

${ }^{1}$ Consultant and IVF Specialist, ${ }^{2}$ Fellow, ${ }^{3}$ Director, Consultant and IVF Specialist, ${ }^{4}$ Director

${ }^{1-3}$ Department of Reproductive Medicine, Nadkarni's 21st Century Hospitals Private Limited and Test Tube Baby Centre Surat, Gujarat, India

${ }^{4}$ Department of Surgery, Nadkarni's 21st Century Hospitals Private Limited and Test Tube Baby Centre, Surat, Gujarat, India

Corresponding Author: Aradhana Kalra, Fellow, Department of Reproductive Medicine, Nadkarni's 21st Century Hospitals Private Limited and Test Tube Baby Centre, Surat, Gujarat, India Phone: +919971817954, e-mail: draradhanakalra@gmail.com
Keywords: Allogenic oocytes, Gonadal dysgenesis, Gonadectomy, Hydrosalpinx, Swyer syndrome.

How to cite this article: Singh P, Kalra A, Nadkarni PK, Nadkarni K. Successful Conception and Delivery in an Unusual Case of 46,XY Pure Gonadal Dysgenesis with Spontaneous Breast Development, Menses, and Bilateral Hydrosalpinx. Int J Infertil Fetal Med 2016;7(2):58-60.

Source of support: Nil

Conflict of interest: None

Date of received: 19-2-2016

Date of acceptance: 29-4-2016

Date of publication: August 2016

\section{INTRODUCTION}

Swyer syndrome is a distinct type of pure gonadal dysgenesis where the patients are phenotypic females without stigmas of Turner's syndrome and have underdeveloped Müllerian structures and fibrotic, primitive, nonproductive gonads. ${ }^{1,2}$ Its incidence is estimated to be 1:80,000 births. ${ }^{3}$ Complex molecular and morphological events must occur at the right sequence and time for the infant to develop into the correct gender. Mutational change in the testis-determining factor gene or sexdetermining region $\mathrm{Y}$ (SRY) may result in lack of testicular determination and hence the female phenotype in these patients; 10 to $20 \%$ of these cases have a deletion in the deoxyribonucleic acid (DNA)-binding region of the SRY gene, while in the remaining 80 to $90 \%$ of cases, the SRY gene is normal and mutations in other testis-determining factors are probably implicated. ${ }^{4}$ Patients are usually diagnosed at adolescence with delayed puberty and primary amenorrhea. ${ }^{1,3,5}$ Classically, hypergonadotropic hypogonadism leads to the absence of spontaneous breast development and menstruation.

In this report, we present a female with normal breast development presenting with secondary amenorrhea and infertility.

\section{CASE REPORT}

A 30-year-old woman presented to our center with primary infertility and secondary amenorrhea for 2 years. Her history revealed that she had normal breast 


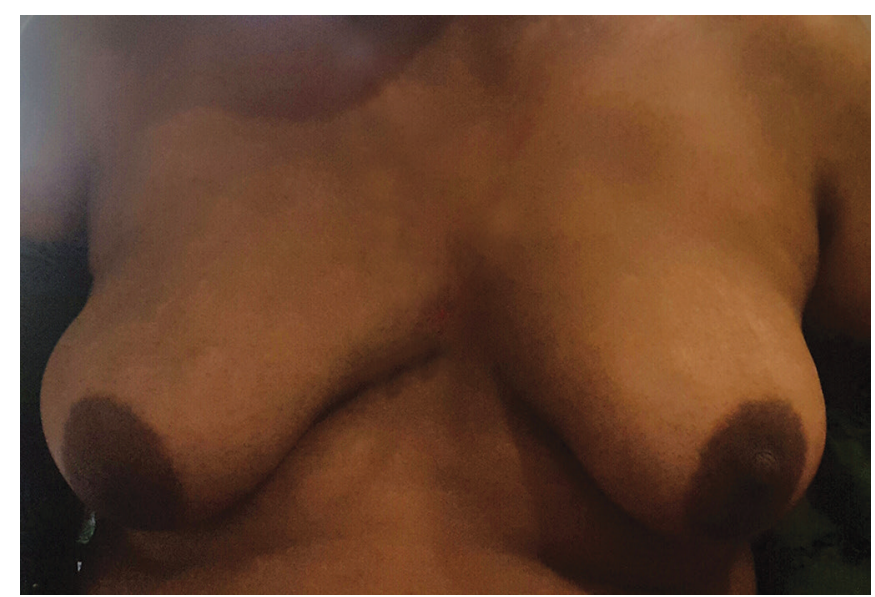

Fig. 1: Bilateral Tanner stage $\mathrm{V}$ breast development

development and attained menarche at 15 years though she had only spotting every 3 to 4 months. She was married at 20 years and had no sexual dysfunction. Family history was unremarkable. On examination, she was phenotypic with height $165 \mathrm{~cm}$, weight $85 \mathrm{~kg}$, body mass index (BMI) $31 \mathrm{~kg} / \mathrm{m}^{2}$, arm span $177 \mathrm{~cm}$, breast and pubic hair Tanner V (Fig. 1), and external genitalia of a normal female. Hormonal evaluation revealed folliclestimulating hormone: $55 \mathrm{IU} / \mathrm{L}$, luteinizing hormone: $15 \mathrm{IU} / \mathrm{L}, \mathrm{E} 2: 47 \mathrm{pg} / \mathrm{mL}$, thyroid-stimulating hormone and prolactin: Normal, and karyotype: 46,XY. Direct sequencing on genomic DNA could not be done. Ultrasonography revealed small uterus of $3.2 \times 2.02 \times 2.47 \mathrm{~cm}$ (Fig. 2), endometrial thickness (ET): $2.9 \mathrm{~mm}$, bilateral hydrosalpinx: $20 \mathrm{~mm}(\mathrm{Rt})$ and $22 \mathrm{~mm}(\mathrm{Lt})$ with small gonads, and normal cervix. Laparoscopic B/L salpingectomy and gonadectomy were done after proper counseling. Histopathology confirmed gonadal streaks, and TB PCR was negative. After correction of her vitamin deficiencies (vitamin D: $7 \mathrm{ng} / \mathrm{mL}$, vitamin B12: $75 \mathrm{pg} / \mathrm{mL}$ ) and four cycles of endometrial preparation and study with estradiol valerate ( $8 \mathrm{mg}$ initially followed by $12 \mathrm{mg}$ ), oocyte donation and intra-cytoplasmic sperm injection (ICSI) with husband's sperm was done. Sequential transfer was done with two day 2, 4-6 cell stage and 1 day 5 , expanded blastocyst transferred. Serum $\beta$-human chorionic gonadotropin on day 16 after transfer was 972 and on day 21 was 6,384 . Her first sonography revealed twin live intrauterine pregnancy. Luteal support was with estradiol valerate $6 \mathrm{mg}$ and micronized progesterone $600 \mathrm{mg}$. The dose of progesterone was increased, and injectable 17 alpha-hydroxyprogesterone was given as the patient had repeated episodes of bleeding. She was on regular antenatal checkups. The patient went into preterm labor and delivered twins vaginally, a boy and girl at 31 weeks weighing 1.55 and $1.3 \mathrm{~kg}$, respectively, and doing fine at 5 months of age.

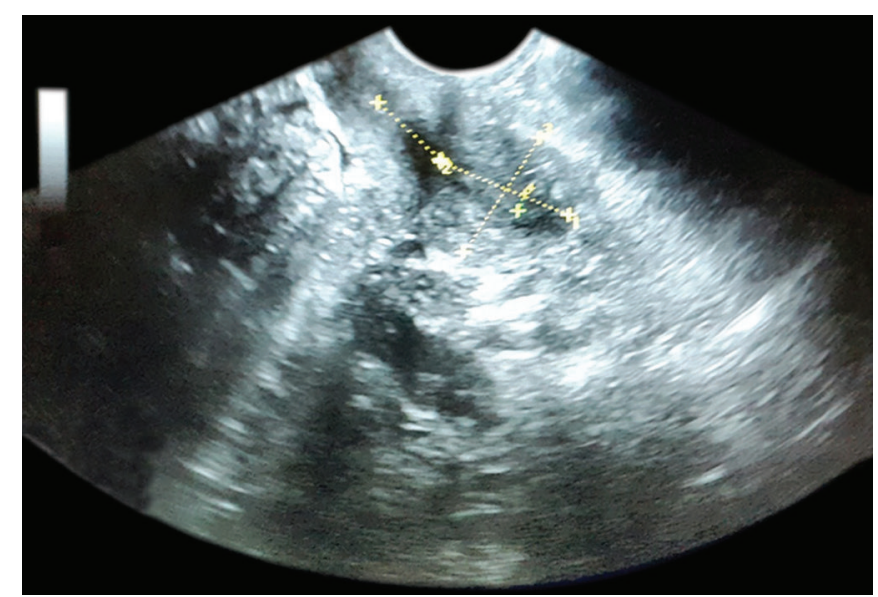

Fig. 2: Transvaginal sonography showing hypoplastic uterus

\section{DISCUSSION}

Swyer syndrome is a rare condition, which can be easily diagnosed if the patients present with classical symptoms. The absence of hormonal activity and lack of adequate estrogen secretion almost always lead to a limitation in the development of secondary sexual characteristics. Patients classically present at adolescence as phenotypic females with normal external genitalia, lack of secondary sexual characters, and primary amenorrhea. High gonadotropin levels, small ovaries without any Turner stigmata, and karyotype confirm the diagnosis. However, patients can also present with spontaneous breast development and/or menstruation, which may delay the diagnosis. To our knowledge, spontaneous breast development was reported in only five cases with Swyer syndrome s-9 $^{5}$ and four cases with spontaneous menstrual cycles ${ }^{5,8-11}$ in the literature. Normal estrogen levels in patients with gonadal dysgenesis were hypothetically attributed to several mechanisms including (i) Production of estrogens by streak gonads at the time of puberty, (ii) peripheral conversion of androgens to estrogens, and (iii) increased sensitivity of breast tissue to estrogens. ${ }^{5,9,12,13}$ There may be hormone production from neoplastic transformation. Four cases with spontaneous menstruation were due to neoplastic estrogen secretion. ${ }^{5,8,10,11}$ The patient presented to us at a later age (30 years) with infertility and secondary amenorrhea and Tanner $\mathrm{V}$ breast and pubic hair. Peripheral aromatization in the adipose tissue could be the probable reason for normal breast development (BMI $31 \mathrm{~kg} / \mathrm{m}^{2}$ ), but, fortunately, no malignancy was detected. Patient underwent laparoscopic B/L salpingectomy with gonadectomy as she had B/Lhydrosalpinx and also underwent in vitro fertilization (IVF)/ICSI.

The hypoplastic uterus in patients with gonadal dysgenesis responds adequately to hormone replacement therapy in terms of enlargement. We considered fundus to internal os measurement $>3 \mathrm{~cm}$ and ET $\geq 8 \mathrm{~mm}$ as 
adequate, before starting the IVF cycle. After four cycles of endometrial preparation, the patient was taken up for IVF. Also uterus does not appear refractory to the process of labor, and vaginal delivery is possible. After literature search, we found 20 patients with Swyer syndrome who conceived between 1989 and 2012, and vaginal delivery was reported in three. ${ }^{1,14}$ Failed induction was reported by only Kan et $\mathrm{al}^{15}$ and Selvaraj et $\mathrm{al}^{16}{ }^{16}$ while others had cesarean section for obstetric complications like malpresentation in twin ${ }_{1}^{17}$ android pelvis, ${ }^{18}$ and breech presentation. ${ }^{19}$

\section{CONCLUSION}

Patients with pure gonadal dysgenesis can present late with normal secondary sexual characters. Because of the high incidence of neoplastic transformation and tendency of germ cell tumors to grow and metastasize rapidly, early diagnosis and gonadectomy should be done. With this report, we emphasize the importance of performing karyotype analysis, which is diagnostic for Swyer syndrome, in all cases with primary or secondary amenorrhea even in the presence of normal breast development. Also, the hypoplastic uterus may have an inherent ability to permit dilatation and labor, but due to few cases reported and cesarean section in majority for obstetric complications without spontaneous/induced labor, it is difficult to ascertain this at the moment.

\section{CLINICAL SIGNIFICANCE}

Early diagnosis and timely management of patients with dysgenetic gonads is important. Pregnancy is possible with allogenic oocytes after adequate enlargement of the uterus. However, single pregnancy is ideal due to a further increased risk of preterm labor in such patients. Genetic counseling and long-term follow-up are required.

\section{REFERENCES}

1. Michala L, Goswami D, Creighton SM, Conway GS. Swyer syndrome: Presentation and outcomes. BJOG 2008 May;115(6): 737-741.

2. Swyer GI. Male pseudohermaphroditism: a hitherto undescribed form. Br Med J 1955 Sep 17;2(4941):709-712.

3. Lee AC, Fong CM. Ovarian choriocarcinoma as the first manifestation of 46,XY pure gonadal dysgenesis. J Pediatr Hematol Oncol 2011 Jan;33(1):29-31.
4. Jager RJ, Anvret M, Hall K, Scherer G. A human XY female with a frameshift mutation in the candidate testis-determining gene SRY. Nature 1990 Nov 29;348(6300):452-454.

5. Ilter E, Haliloğlu B, Akin FT, Karaman A, Ozden S. Pure 46,XY gonadal dysgenesis (Swyer syndrome) with breast development and secondary amenorrhea. Gynecol Obstet Invest 2008;66(3):214-216.

6. Dumic M, New MI, Lin-Su K, McElreavey K, Leibel NI, Ciglar S, Nimkarn S, Vinci G, Wilson J, Lasan R. Report of fertility in a woman with a predominantly $46, \mathrm{XY}$ karyotype in a family with multiple disorders of sexual development. Adv Exp Med Biol 2011;707:169-170.

7. Karimian N, Ghadakzadeh S, Eshraghi M. Swyer syndrome in a woman with pure $46, \mathrm{XY}$ gonadal dysgenesis and a hypoplastic uterus: a rare presentation. Fertil Steril 2010 Jan;93(1):267. e13-267.e14.

8. Stilinovic K, Tomasíc D, Blazek L, Grljusic V, Butkovic D. [Secondary amenorrhea in gonadal dysgenesis with a 46, XY karyotype.] Jugosl Ginekol Perinatol 1988 Jan-Apr;28(1-2): 33-35.

9. Tanwani LK, Chudgar D, Murphree SS, Eblen AC, Mokshagundam SP. A case of gonadal dysgenesis, breast development, Graves' disease, and low bone mass. Endocr Pract 2003 May-Jun;9(3):220-224.

10. Behtash N, Karimi Zarchi M. Dysgerminoma in three patients with Swyer syndrome. World J Surg Oncol 2007 Jun 23;5:71.

11. McClure N, Henry O, Harley JM. Pure XY gonadal dysgenesis presenting as secondary amenorrhea. A case report. J Reprod Med 1992 Mar;37(3):291-292.

12. Warner BA, Monsaert RP, Stumpf PG, Kulin HE, Wachtel SS. $46, \mathrm{XY}$ gonadal dysgenesis: is oncogenesis related to $\mathrm{H}-\mathrm{Y}$ phenotype or breast development? Hum Genet 1985;69(1):79-85.

13. Zieliñska D, Zajaczek S, Rzepka-Górska I. Tumors of dysgenetic gonads in Swyer syndrome. J Pediatr Surg 2007 Oct;42(10):1721-1724.

14. Siddique H, Daggett $P$, Artley K. Successful term vaginal delivery in a 46,XY woman. Int J Gynaecol Obstet 2008 Jun;101(3):298-299.

15. Kan AK, Abdalla HI, Oskarsson T. Two successful pregnancies in a 46,XY patient. Hum Reprod 1997 Jul;12(7):1434-1435.

16. Selvaraj K, Ganesh V, Selvaraj P. Successful pregnancy in a patient with a 46,XY karyotype. Fertil Steril 2002 Aug;78(2): 419-420.

17. Chen MJ, Yang JH, Mao TL, Ho HN, Yang YS. Successful pregnancy in a gonadectomized woman with $46, \mathrm{XY}$ gonadal dysgenesis and gonadoblastoma. Fertil Steril 2005 Jul;84(1):217.

18. Cornet D, Alvarez S, Antoine JM, Tibi C, Mandelbaum J, Plachot M, Salat-Baroux J. Pregnancies following ovum donation in gonadal dysgenesis. Hum Reprod1990 Apr;5(3): 291-293.

19. Tulic I, Tulic L, Micic J. Pregnancy in patient with Swyer syndrome. Fertil Steril 2011 Apr;95(5):1789.e1-1789.e2. 